\title{
Experimental and Numerical Investigations on the Behaviour of Masonry Walls Reinforced with an Innovative Sisal FRCM System
}

\author{
Claudia Brito de Carvalho Bello ${ }^{1, a^{*}}$, Antonella Cecchi ${ }^{1, b}$, \\ Emilio Meroi ${ }^{1, c}$, Daniel V. Oliveira ${ }^{2, d}$ \\ ${ }^{1}$ Department of Architecture Construction Conservation, Università IUAV di Venezia, Italy \\ ${ }^{2}$ ISISE, Department of Civil Engineering, University of Minho, Portugal \\ adecarvalho@iuav.it, ${ }^{b}$ cecchi@iuav.it, ${ }^{c}$ meroi@iuav.it, ${ }^{d}$ danvco@civil.uminho.pt
}

Keywords: Sisal fibres, FRCM, Masonry panels, strengthening, Diagonal compression tests

\begin{abstract}
An experimental and numerical investigation on an innovative composite reinforced with sisal fibers for masonry strengthening is presented in this paper. A FEM numerical approach is also developed, based on diagonal compression test results, to simulate the shear in-plane response of unreinforced masonry panels (URM) and masonry strengthened with a Fibre Reinforced Cementitious Matrix (FRCM) composite system made with sisal fibers (RM-SISAL).
\end{abstract}

\section{Introduction}

The use of Fibre Reinforced Cementitious Matrix (FRCM) composites constitutes an efficient retrofitting option to increase the mechanical resistance and displacement capacity of existing structures. In particular, these composite systems can be properly adopted with reference to ordinarily masonry walls, which typically present brittle behaviour and poor tensile resistance response [1-3].

This work deals with a part of a large experimental research that investigates the behaviour of composite systems using sisal fibres, aiming at establishing whether this kind of natural material can efficiently replace partially the synthetic fibres currently used for structural reinforcement.

Diagonal compression tests have been carried out on non-reinforced masonry panels and single-lap and direct-shear tests were performed on a FRCM system made with sisal fibers.

This work also takes into account the mechanical behaviour of masonry wallets reinforced with a glass-FRCM system to investigate its mechanical response and to set the numerical models.

On the basis of experimental results, a FEM-based numerical approach was adopted to characterize the sisal-based FRCM performance and to evaluate the effectiveness of this composite system in terms of resistance and ductility characteristics.

\section{Experimental program and test procedure}

The experimental tests here presented are a part of ongoing Fibre Net Srl campaign to investigate different coating systems for masonry strengthening. Diagonal compression tests are being performed on unreinforced and reinforced brick masonry panels with different types of mortar coating. This paper reports the results of diagonal compression tests carried out in a previous step of this experimental campaign [3] on solid brick unreinforced specimens (URM and RM-GLASS), used to investigate the reinforced masonry mechanical response and to set the numerical models. The test set-up exploited (fig.1) allows the application of compression loads on the diagonal of the specimens through a hydraulic actuator (load capacity of $950 \mathrm{kN}$ ). The tests were carried out under force control. A sequence of loading-unloading cycles with steps of $25-50 \mathrm{kN}$ was performed up to reaching the peak load (when diagonal crack occurs) and the tests continued under displacement control until diagonal displacement values reach almost $10 \mathrm{~mm}$. Four linear variable displacement transducers (LVDT) were placed on both faces, along the specimen diagonals, and connected to an electronic acquisition device. 


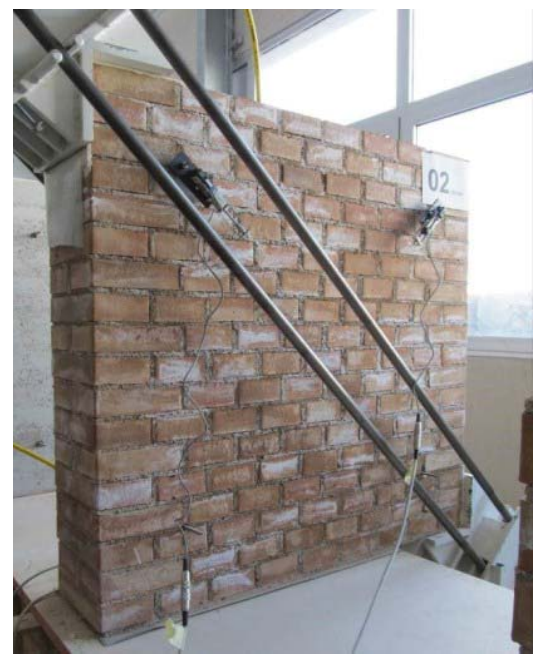

(a)

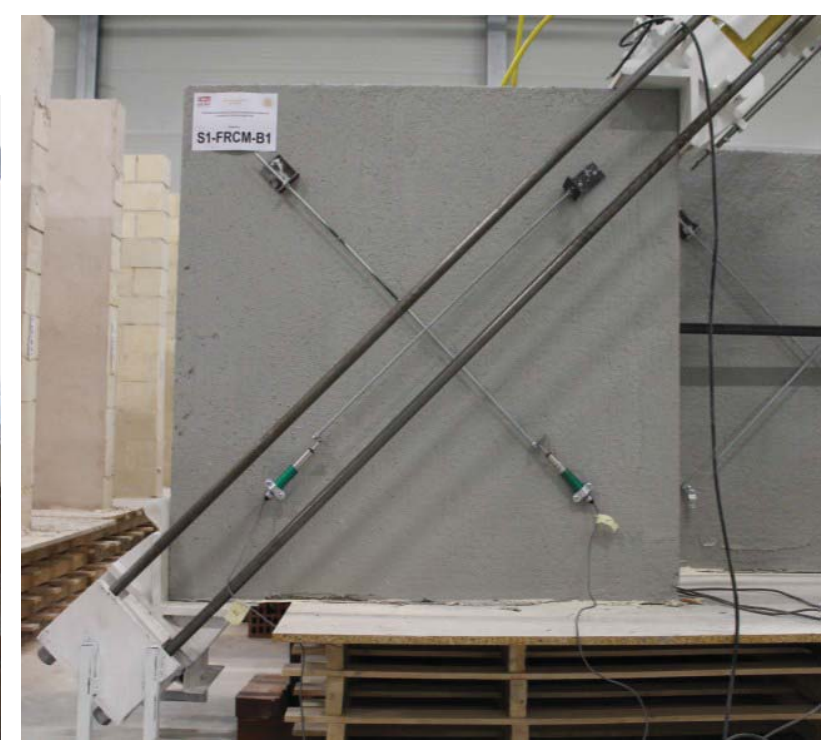

(b)

Fig. 1: Diagonal compression test set up: (a) unreinforced; (b) reinforced masonry specimens (photos by Fibre Net Srl)

Masonry specimens are square panels $\left(1160 \times 1160 \mathrm{~mm}^{2}\right)$ made with solid clay bricks arranged as headers, with $250 \mathrm{~mm}$ thick while the joints are made of hydraulic lime mortar, with $10 \mathrm{~mm}$ thick (fig. 1a). Bricks average compressive strength is $44 \mathrm{MPa}$. The mortar mechanical characteristics were determined by testing cylinders $(100 \mathrm{~mm}$ diameter and $200 \mathrm{~mm}$ height $)$ and prisms under compression and flexure, carried out by reference to UNI codes (UNI EN 12390-3:2009 and UNI EN 12390-6:2010). Tests results allowed to obtain 1.15 MPa and $0.31 \mathrm{MPa}$ as average values for compressive and tensile strength, respectively, see also Table 1.

Table 1: Mechanical properties of masonry components

\begin{tabular}{lll}
\hline Brick mechanical properties & & \\
\hline Compressive strength (MPa) & $\left(f_{c}\right)$ & 44.00 \\
\hline Mortar mechanical properties & & \\
\hline Compressive strength (MPa) & $\left(f_{c}\right)$ & 1.15 \\
Tensile strength $(\mathrm{MPa})$ & $\left(f_{t}\right)$ & 0.31
\end{tabular}

The FRCM systems investigated in the experimental Fibre Net $\mathrm{Srl}$ campaign comprehend different masonry reinforcements made with different fibers for the textiles or performed nets (i.e. glass, carbon, steel, sisal). Tests on masonry reinforced with glass meshes were performed with different mortars and substrates (fig.1b), while reinforcement coating using sisal fibres applied on solid brick panels are still ongoing. The reinforcement technique consists on applying consecutively, on both sides of masonry, a thin layer of mortar, then a mesh grid or textile composite and finish with a second thin layer of mortar. In the Fibre Net Srl retrofitting solutions usually connectors bars are used for system anchorage.

The Sisal FRCM is constituted by a hydraulic lime mortar and a non-woven textile made with sisal fibers. Mortar mechanical properties, determined by testing cylinders $(100 \mathrm{~mm}$ diameter and $200 \mathrm{~mm}$ height) and prisms under compression and flexure, carried out by reference to UNI codes (UNI EN 12390-3:2009 and UNI EN 12390-6:2010) are $7.35 \mathrm{MPa}$ for compressive strength, $1.05 \mathrm{MPa}$ for tensile strength and Young's modulus equal to $14425 \mathrm{MPa}$. The sisal net has a mesh $200 \times 200 \mathrm{~mm}^{2}$ and the wires are realized with three sisal yarns twisted. Tensile tests on sisal yarns and wires were performed to set material mechanical properties (fig. 2b). Furthermore, tensile and 
shear tests according to RILEM TC-250 CSM round robin tests procedure [4] were carried out with a sisal FRCM system and permit to establish the composite mechanical behaviour (fig.2). Mechanical parameters are briefly reported in Table 2.

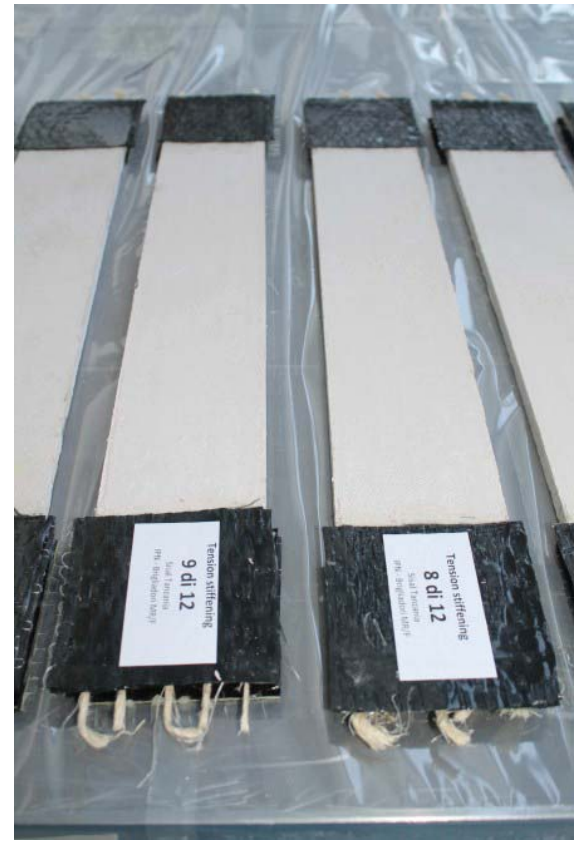

(a)

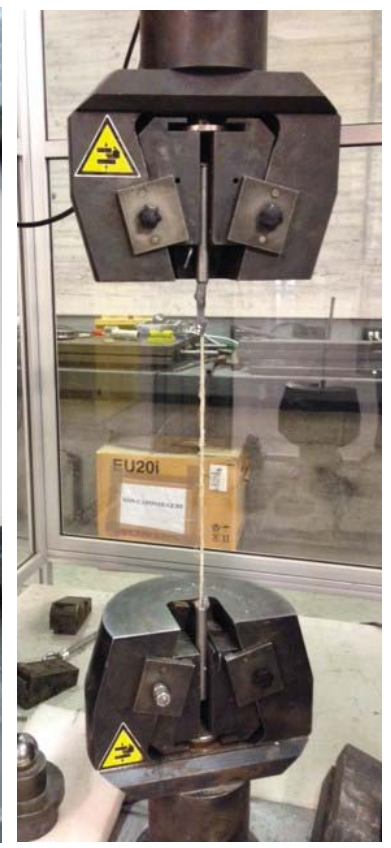

(b)

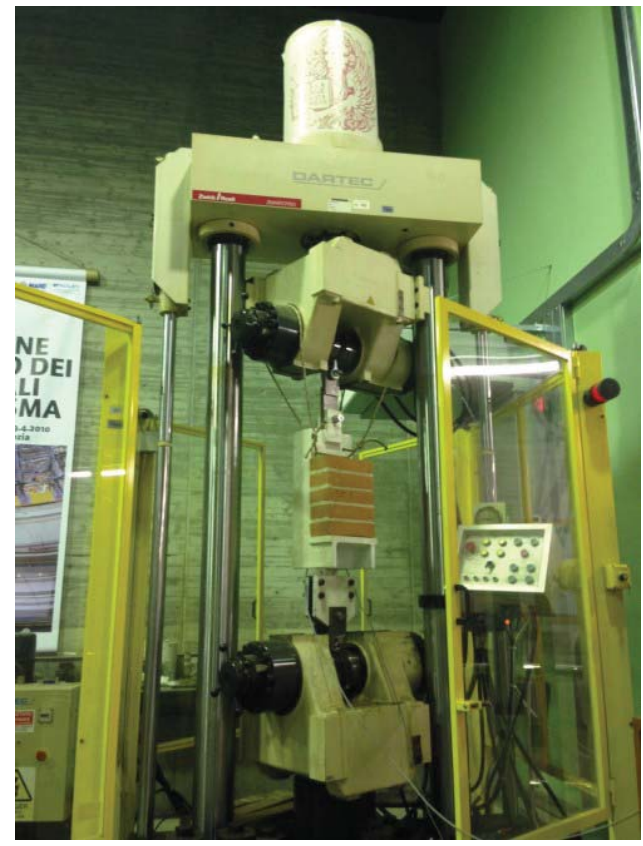

(c)

Fig. 2: Round robin tests and specimens: (a) Sisal FRCM sample; (b) tensile test on sisal yarn;

(c) shear test with sisal FRCM on brick masonry substrate [4]

Table 2: Sisal FRCM mechanical properties

\begin{tabular}{llr}
\hline Mortar matrix mechanical properties & & \\
\hline Young modulus (MPa) & $(E)$ & 14429 \\
Compressive strength (MPa) & $\left(f_{c}\right)$ & 7.35 \\
Tensile strength (MPa) & $\left(f_{t}\right)$ & 1.05 \\
\hline
\end{tabular}

Sisal yarns mechanical properties

Young modulus (MPa)

(E)

7142

Tensile strength (MPa)

$\left(f_{t}\right)$

500.00

\section{Diagonal compression test results}

The results of diagonal compressive tests performed with non-reinforced masonry specimens (URM) reveals a brittle behaviour response, with evident diagonal cracks on the bed and head mortar joints along the loading direction. The experimental results on URM and masonry reinforced with glass net specimens (RM-GLASS) are taken into account to understand the coating mechanical response and to set the FEM models. The glass reinforcement has the same mortar of sisal-FRCM, which mechanical properties are reported in table 2. The glass grid has $3.8 \mathrm{~cm}^{2}$ fiber area with parallel and twisted fiber wires. By reference to URM test results, RM-GLASS showed a better post-peak response, with a softening behaviour, up to the ultimate failure stress. Therefore, the mortar coating was able to increase shear strength and the overall ductility of brick masonry panels [3]. In table 3 , the main average values of the the maximum diagonal compressive load $\left(\mathrm{P}_{\max }\right)$ and the ratio between the maximum load of RM and URM specimens $\left(\mathrm{P}_{\max , \mathrm{RM}} / \mathrm{P}_{\max , U R M}\right)$ are reported. The values have been calculated according to RILEM TC 76-LUM [5] standard. The " $P_{\max }$ " value refers to the average wallet maximum shear strength and " $\mathrm{P}_{\max , \mathrm{RM}} / \mathrm{P}_{\max , \mathrm{URM}}$ " refers to the relative increase of resistance. 
Table 3: Diagonal compression tests results

\begin{tabular}{lcc}
\hline Specimen* & $\mathrm{P}_{\max }[\mathrm{KN}]$ & $\mathrm{P}_{\max , R M} / \mathrm{P}_{\max , \text { URM }}$ \\
\hline URM & 192 & - \\
RM-GLASS & 324 & 1.69 \\
\hline
\end{tabular}

\section{Numerical model}

Studies on sisal FRCM trough a numerical modelling approach allow to predict the system mechanical behaviour and also to help on the composite design definition. Based on experimental results, a FEM-based numerical approach was adopted to characterize the sisal-based FRCM performance. The numerical modelling and analysis were performed with the commercial software TNO DIANA software [6]. The experimental data validates the numerical results and constitutes a basis of numerical modelling for the predictions of the sisal coating mechanical behaviour.

A macro-modelling approach based on smeared crack theory is adopted to simulate the masonry panel. Then, bricks and mortar are considered as a homogenized material, through a total strain rotating crack model (TSCM), with an exponential response in tension and parabolic in compression. The mesh consists of twenty-nodded brick elements denoted as CHX60 elements in Diana software. Material properties are assigned in agreement with experimental results and are given in Table 4.

Table 4: Mechanical parameters of masonry material

\begin{tabular}{lcr}
\hline Masonry mechanical parameters & & \\
\hline Young modulus $(\mathrm{MPa})$ & $(E)$ & 5000 \\
Poisson's ratio & $(n)$ & 0.15 \\
Compressive strength $(\mathrm{MPa})$ & $\left(f_{c}\right)$ & 5.0 \\
Tensile strength $(\mathrm{MPa})$ & $\left(f_{t}\right)$ & 0.2 \\
Fracture energy in compression $(\mathrm{N} / \mathrm{mm})$ & $\left(G_{f c}\right)$ & 8.0 \\
Fracture energy in tension $(\mathrm{N} / \mathrm{mm})$ & $\left(G_{f t}\right)$ & 0.02
\end{tabular}

The FRCM composite can be considered as a homogeneous material with an embedded reinforcement, for simulating the material nonlinear behaviour [7]. The mortar matrix mesh adopted is constituted by quadrilateral eight-noded shell elements with $40 \mathrm{~mm}$ thick. Also the mortar is modelled as TSCM material, with a JSCE softening behaviour in tension and parabolic in compression. The sisal grid is modelled as reinforcement fully embedded in the mortar matrix, using the grid elements present in DIANA package. The material is considered with an elastic behaviour until the ultimate tensile strength obtained by experimental tests performed on the sisal yarns. All materials parameters used in the FEM model are reported in table 5. The geometry design checks inputs are the real dimensions of sisal grid. The fiber element cross-section is equal to $4 \mathrm{~mm}^{2}$, distributed on a net of $20 \times 20 \mathrm{~mm}^{2}$.

Firstly, a FEM model of URM panel is calibrated with experimental results (fig. 3a). Then, the monotonic analysis of RM-SISAL FEM model (fig. 3b) predicts the shear mechanical response for reinforced panels. 
Table 5: Mechanical parameters of FRCM: mortar matrix and sisal grid

\begin{tabular}{lcr}
\hline Mortar matrix mechanical parameters & & \\
\hline Young modulus (MPa) & $(E)$ & 14429 \\
Poisson's ratio & $(n)$ & 0.20 \\
Compressive strength $(\mathrm{MPa})$ & $\left(f_{c}\right)$ & 7.35 \\
Tensile strength $(\mathrm{MPa})$ & $\left(f_{t}\right)$ & 1.05 \\
Plateau end strain & $(P S)$ & 0.0002 \\
Power C & $(C)$ & 0.40
\end{tabular}

\begin{tabular}{llr}
\hline Sisal grid reinforcement parameters & & \\
\hline Young modulus $(\mathrm{MPa})$ & $(E)$ & 7142 \\
Tensile strength $(\mathrm{MPa})$ & $\left(f_{t}\right)$ & 500.00
\end{tabular}

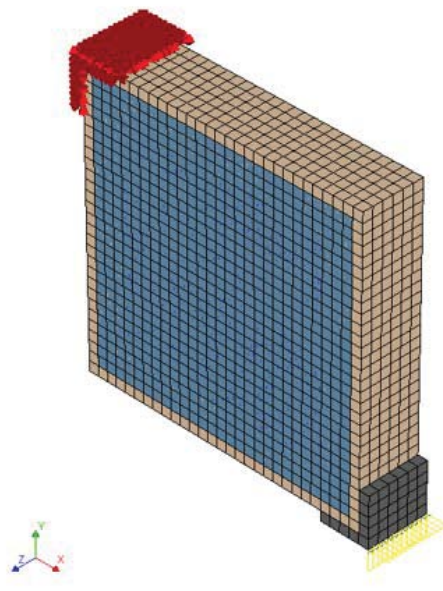

(a)

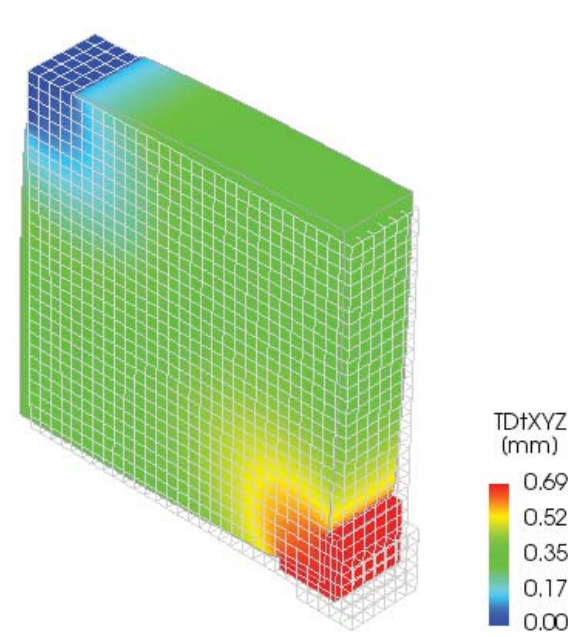

(b)

Fig. 3: Diagonal compression test FEM model: (a) 3d geometry; (b) displacements contours over deformed configuration at peak load (URM)

The output value as maximum diagonal compressive load $\left(\mathrm{P}_{\max }\right)$ is $360 \mathrm{kN}$. The ratio between the maximum load of RM and URM specimens $\left(\mathrm{P}_{\max , \mathrm{RM}} / \mathrm{P}_{\max , \mathrm{URM}}\right)$ is 1.88 , as reported in Table 6.

Table 6: FEM results

\begin{tabular}{lcc}
\hline URM & 199 & - \\
\hline RM-SISAL & 360 & 1.88 \\
\hline
\end{tabular}

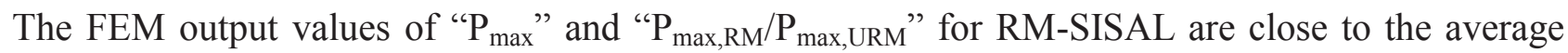
values obtained experimentally with RM-GLASS samples showed in table 3. The numerical simulation for masonry walls reinforced with sisal-FRCM predicts an increment in the shear strength resistance at the peak load similar to those reinforced with glass fibers and a similar matrix mortar.

\section{Acknowledgments}

The authors acknowledge the support of the research project PRIN 2015 (under grant 2015JW9NJT_014, project "Advanced mechanical modeling of new materials and structures for the solution of 2020 Horizon challenges") and Fibre Net Srl (Pavia di Udine, Italy) for the support given in the experimental tests. This work was partly financed by FEDER funds through the Competitivity Factors Operational Programme - COMPETE and by national funds through FCT Foundation for Science and Technology within the scope of projects POCI-01-0145-FEDER007633. 


\section{References}

[1] G.de Felice, S. De Santis, L. Garmendia et al, Mortar-based systems for externally bonded strengthening of masonry, Materals and Structures 47: 2021. doi:10.1617/s11527-014-0360-1 (2014).

[2] C. Menna, D. Asprone, M. Durante, A. Zinno, A. Balsamo, A. Prota, Structural Behaviour of Masonry Panels Strengthened with an Innovative Hemp Fibre Composite Grid, Construction and Building Materials 100: 111-121. doi:10.1016/j.conbuildmat.2015.09.051 (2015).

[3] N. Gattesco and I. Boem, Experimental and Analytical Study to Evaluate the Effectiveness of an in-Plane Reinforcement for Masonry Walls using GFRP Meshes, Construction and Building Materials 88: 94-104. doi:10.1016/j.conbuildmat.2015.04.014 (2015).

[4] De Santis S., Carozzi F.G., de Felice G., Poggi C. Test methods for Textile Reinforced Mortar systems. Composites Part B: Engineering. DOI: 10.1016/j.compositesb.2017.03.016 (2017).

[5] RILEM TC. 76-LUM. Diagonal tensile strength tests of small wall specimens. In: RILEM recommendations for the testing and use of constructions materials. London, UK: E\&EN SPON; 1994. p. 488-9 (1994).

[6] DIANA, Displacement analyser finite element software package, v.10.1, DIANA FEA BV, Delft, The Netherlands (2017).

[7] X. Wang, B. Ghiassi, D.V. Oliveira, C.C. Lam, Modelling the nonlinear behaviour of masonry walls strengthened with textile reinforced mortars, Engineering Structures 134; 11-24 (2017). 